\title{
UK Renal Registry 11th Annual Report (December 2008): Chapter 15 The UK Renal Registry, UKRR database, validation and methodology
}

\author{
David Ansell $^{\mathrm{a}}$ and Charles RV Tomson ${ }^{\mathrm{a}}$ \\ aUK Renal Registry, Bristol, UK
}

\section{Key Words}

Data validation - Methodology · Renal Registry

\begin{abstract}
The UK Renal Registry receives encrypted data extracts quarterly from each centre providing Renal Replacement Therapy (RRT) in England, Wales and Northern Ireland. Summary data is received from the Scottish Renal Registry to allow national statistics to be compiled. Data from patients receiving haemodialysis in satellite units or at home are reported through the main renal centre. Data from patients with functioning kidney transplants are reported through the centre providing routine clinical follow-up. The data are extracted from a variety of IT systems with varying functionality and no common messaging system, necessitating extensive data validation and cleaning prior to analysis. Growing confidence in the analyses since the inception of the Registry in 1995 has allowed de-anonymised centre-specific analyses of all outcomes, including survival, to be published, although incomplete data returns for primary renal diagnosis and comorbidity at start of RRT limit ability to adjust for case-mix.
\end{abstract}

(C) 2009 S. Karger AG, Basel

1160-2110/09/1115-0277\$26.00/0

Fax +4161306 1234 E-Mail karger@karger.ch www.karger.com
Accessible online at: www.karger.com/nec

\section{Introduction}

The UK Renal Registry (UKRR) started as a pilot project in 1995 in collaboration with 8 renal centres that operated information systems that reliably captured information on clinical care of patients undergoing Renal Replacement Therapy (RRT). Software was written that allowed information from these systems to be extracted, encrypted, and sent to the UKRR for analysis. The first Annual Report was published in 1998; all Annual Reports can be downloaded from the UKRR's website, www.renalreg.org. Since then, funding has been secured, the dataset has grown, and every adult renal centre in England, Wales and Northern Ireland has a suitable information system in place for submitting data to the UKRR. This chapter builds on previous descriptions of the function of the UKRR [1-4].

The Scottish Renal Registry [5] is funded and functions independently, but submits summary data to the UKRR, enabling the assembly of national information on incidence, prevalence, and outcomes of RRT.

In the early phase of UKRR reporting, centres were anonymised; now, each centre sending data is identified by name in the analyses published in the UKRR's 
annual reports, including analyses of centre-specific ageadjusted survival. This chapter describes in detail how these data are obtained, validated, corrected, and analysed.

\section{Organisation of delivery of RRT in the UK}

From a history of under-provision [6-10], there has been massive growth in provision of RRT in the UK, driven partly by analyses from early UKRR reports and national surveys [11-16]. RRT for adults is currently provided by 72 centres within the UK and RRT for children is provided by 13 paediatric renal centres. Although since 1997 there has been some amalgamation where there was more than one centre in the same city (e.g. Glasgow 3 centres into 1, Leeds 2 centres into 1, West London 3 centres into 1), there has also been creation of new renal centres (e.g. York previously part of Leeds and Aintree previously part of Liverpool) as satellite dialysis units have expanded to become independent renal centres.

These renal centres are generally based within large district or regional hospitals. All the large and medium sized adult renal centres operate satellite dialysis units ( 46 out of 72 UK centres), which may be free-standing or based in a hospital or other healthcare setting. Medical supervision of treatment in satellite units is provided by nephrologists based in renal centres. Growth in satellite provision has largely been responsible for the growth in haemodialysis capacity [14]. Satellite units may be either staffed and funded solely through the NHS or operated by commercial providers under contract, either to the local NHS Trust accommodating the parent renal centre, or on an 'Independent Sector Treatment Centre' basis, in which the contract is held by the Secretary of State for Health. In all cases, medical supervision of RRT is provided by nephrologists paid by the NHS based in renal centres. Fully private, non-NHS funded provision of RRT in the UK is used almost exclusively by visitors from abroad. Provision of haemodialysis away from home ('holiday dialysis') is paid for by the parent renal centre, but capacity to accommodate patients needing such treatment varies with some provided by commercial centres. All main renal centres also offer peritoneal dialysis (although this may be provided by an adjacent centre), but only a few satellite dialysis units also provide this treatment modality.

Home haemodialysis programmes are run by 46 adult renal centres, some also accept referrals of suitable patients from neighbouring centres that do not offer this treatment modality.

Of the 72 adult renal centres, 23 also perform kidney transplantation. Patients are referred for transplantation from non-transplanting centres and from within the transplant centre. Non-transplanting centres may refer their patients to more than one transplant centre, usually on geographical grounds. Eight of the transplant centres in the UK are designated supra-regional centres for simultaneous kidney and pancreas transplantation, and accept referrals from neighbouring transplant and nontransplant centres. Allocation of organs retrieved from beating-heart deceased donor transplants is co-ordinated by the Directorate of Organ Donation and Transplantation (ODT, formerly UK Transplant) within NHS Blood and Transplant (NHSBT) according to a nationally agreed organ allocation scheme [17].

Organs retrieved from non-heartbeating donors are allocated according to local agreements, but are all registered with NHSBT, as are all UK based live donor transplants. NHSBT collects detailed information on kidney donors (including demographic information and ischaemic times) and on HLA typing of donors and recipients. Transplants that occur outside the UK are not recorded by NHSBT, although when these patients return to the UK with a functioning transplant, the UK Renal Registry will pick up this modality change and follow their outcomes.

All patients entitled to NHS care are registered with a general practitioner (primary care physician) who coordinates care and decides on referral for specialist investigation. The Quality and Outcomes Framework, a payment for performance incentive scheme for primary care in the UK, provides financial incentives for the maintenance in each general practice of a register of patients with CKD 3-5, together with markers relating to blood pressure control and receipt of ACE inhibitors or Angiotensin Receptor Blockers where indicated. National data on practice-level reported prevalence of CKD and on achievement of each quality marker are collated and published using the Quality Management and Analysis System (QMAS) [18] by the NHS Information Centre $[18,19]$. National guidelines state that all patients with CKD4 and CKD5 should be discussed with or referred to renal physicians by their primary care physicians $[20,21]$. The date of first referral to a nephrologist is included in the dataset for patients receiving RRT by renal centres and is reported to the UKRR. However, data on patients with advanced kidney disease receiving 'conservative', 'palliative', or 'supportive' care, 
i.e. those patients with whom an active decision is made not to undertake RRT (usually for reasons of personal choice, frailty, comorbidity or limited life expectancy) are not currently submitted to the UKRR, although a pilot project is under way to extract data on patients with CKD5 from renal centre IT systems.

\section{Information systems in use in renal centres in the UK in 2007-2009}

Table 15.1 gives the information system currently in use in each adult renal centre, together with any immediate plans of which the UKRR is aware to move to another system.

The functionality of these systems was studied in a national survey in 2006 [22].
Most of these renal IT systems evolved and now operate semi-independently of other information systems within the hospital accommodating the renal centre, with bespoke software written to allow automatic uploading from laboratory systems (locally based and from other hospitals), from the patient administration data (PAS) and output from haemodialysis machines. This independence from the main hospital IT has allowed flexibility, for instance in the creation of locally specific data screens to support local care pathways, but with the disadvantage that this information is held in a 'silo' not visible to other hospital clinicians who may be involved in the care of these patients. These existing renal systems are currently not integrated with the new generation of electronic patient records (EPR). As healthcare computing in the UK evolves (supported in England by Connecting for Health, in Wales by Informing Healthcare, in Northern Ireland by Health and Social

Table 15.1. IT systems in UK adult renal centres

\begin{tabular}{|c|c|c|}
\hline Adult centre & Current renal IT system & 2009 changes \\
\hline \multicolumn{3}{|l|}{ England } \\
\hline Basildon & Mediqal eMed & \\
\hline Birmingham QEH & In-house developed & \\
\hline Birmingham Heartlands & CCL Proton & \\
\hline Bradford & CCL Proton & \\
\hline Brighton & CCL Clinical vision & \\
\hline Bristol & CCL Proton & \\
\hline Cambridge & In-house developed & \\
\hline Canterbury & Chi Renalplus & \\
\hline Carlisle & CCL Proton & \\
\hline Carshalton & CCL Proton & \\
\hline Chelmsford & Mediqal eMed & \\
\hline Colchester & Fresenius & \\
\hline Coventry & CCL Proton & \\
\hline Derby & Vitalpulse Vitaldata & \\
\hline Doncaster & Mediqal eMed & \\
\hline Dorset & Mediqal eMed & \\
\hline Dudley & CCL Proton & Mediqal eMed \\
\hline Exeter & CCL Proton & \\
\hline Gloucester & CCL Proton & Vitalpulse Vitaldata \\
\hline Hull & CCL Proton & \\
\hline Ipswich & Baxter & \\
\hline Leeds & CCL Proton & \\
\hline Leicester & CCL Proton & \\
\hline Liverpool Aintree & CCL Proton & Cybernius Cyberen \\
\hline Liverpool RI & CCL Proton & Cybernius Cyberen \\
\hline London St Barts & Renalware & \\
\hline London St Georges & CCL Clinical vision & \\
\hline London Guys & CCL Proton & In-house developed \\
\hline London West & In-house developed & CCL Proton \\
\hline London Kings & Renalware & \\
\hline London Royal Free & Renalware & \\
\hline Manchester Hope & In-house developed & \\
\hline
\end{tabular}


Table 15.1. Continued

\begin{tabular}{|c|c|c|}
\hline Adult centre & Current renal IT system & 2009 changes \\
\hline $\begin{array}{l}\text { Manchester RI } \\
\text { Middlesbrough } \\
\text { Newcastle } \\
\text { Norwich } \\
\text { Nottingham } \\
\text { Oxford } \\
\text { Plymouth } \\
\text { Portsmouth } \\
\text { Preston } \\
\text { Reading } \\
\text { Sheffield } \\
\text { Shrewsbury } \\
\text { Southend } \\
\text { Stevenage } \\
\text { Stoke } \\
\text { Sunderland } \\
\text { Truro } \\
\text { Wirral } \\
\text { Wolverhampton } \\
\text { York }\end{array}$ & $\begin{array}{l}\text { CCL Clinical vision } \\
\text { CCL Proton } \\
\text { CCL Clinical vision } \\
\text { Mediqal eMed } \\
\text { CCL Proton } \\
\text { CCL Proton } \\
\text { CCL Proton } \\
\text { CCL Proton } \\
\text { CCL Proton } \\
\text { CCL Proton } \\
\text { CCL Proton } \\
\text { Chi Renalplus } \\
\text { CCL Proton } \\
\text { Chi Renalplus } \\
\text { Cybernius Cyberen } \\
\text { CCL Proton } \\
\text { CCL Proton } \\
\text { In-house developed } \\
\text { CCL Proton } \\
\text { CCL Proton }\end{array}$ & Vitalpulse Vitaldata \\
\hline $\begin{array}{l}\text { Wales } \\
\text { Bangor } \\
\text { Cardiff } \\
\text { Clwyd } \\
\text { Swansea } \\
\text { Wrexham }\end{array}$ & $\begin{array}{l}\text { Baxter } \\
\text { CCL Proton } \\
\text { Fresenius } \\
\text { CCL Proton } \\
\text { Chi Renalplus }\end{array}$ & $\begin{array}{l}\text { Vitalpulse Vitaldata } \\
\text { Vitalpulse Vitaldata }\end{array}$ \\
\hline $\begin{array}{l}\text { Northern Ireland } \\
\text { Antrim } \\
\text { Belfast } \\
\text { Derry } \\
\text { Newry } \\
\text { Tyrone } \\
\text { Ulster }\end{array}$ & $\begin{array}{l}\text { Mediqal eMed } \\
\text { Mediqal eMed } \\
\text { Mediqal eMed } \\
\text { Mediqal eMed } \\
\text { Mediqal eMed } \\
\text { Mediqal eMed }\end{array}$ & \\
\hline
\end{tabular}

Care and in Scotland by NHS Scotland), there is a consensus that the EPR should include all aspects of this functionality, although now it is no longer proposed that this be provided through a single software solution. In England, the contract with Local Service Providers (section 167.2.1) requires that all Trusts support a computer package capable of supporting the UK Renal Registry Dataset.
In 2008 the NHS in England finalised a range of Framework Contracts through open competition to provide additional capacity and capability in the supply of IT services to the NHS. These contracts are not intended to replace the contracts already let for the National Programme for IT. The procurement of the Framework Contracts for Additional Supply Capability and Capacity (ASCC) was initiated with the publication 
of an OJEU Notice in March 2007 (the Official Journal of the European Union). The Frameworks will enable the streamlined procurement of IT systems and services from suppliers to cover specialist areas such as renal, coronary heart disease, e-prescribing, critical care, social care, child health etc. (http://www.connectingfor health.nhs.uk/industry/ascc/appointedlot2).

\section{The UKRR dataset and the National Renal Dataset}

In England and Wales, the National Renal Dataset provides the specification of information to be collected by the NHS to support implementation of the National Service Framework for Renal Services, which set out a national policy and ten year plan for care of patients with kidney disease [23, 24], supported by an Information Strategy that included the development of a National Renal Dataset $[25,26]$, collection of which will be used by kidney care services to assess their achievement of the quality standards and to improve kidney care for patients.

The National Renal Dataset has been approved as a Full Operational Information Standard by the Information Standards Board for Health and Social Care. This is the first approved dataset covering the whole of a specialty. A Dataset Change Notice (DSCN) has been issued to formally notify English NHS Trusts and information system suppliers of this approval [27]. The same dataset is being adopted by the Welsh government. This makes it a legal requirement for Trusts to return the full dataset and obliges system suppliers within the National Programme for IT to enable Trusts to record the data covered by the DSCN. Some parts of the dataset are to be returned electronically to the UKRR: those parts currently returned to NHS Blood and Transplant may continue to be returned using paper returns.

Implementation of the dataset is mandated in two phases,

- collection of 693 data items from May 2009 and

- collection of an additional 188 data items from April 2011.

\section{Data extraction from renal centre information systems}

Each centre submits a quarterly data extract to the UKRR. This requires software routines to extract these data items from the information system and transmit them in the required file format. Running these routines is the responsibility of the renal centre, although the UKRR has historically provided advice and support to those centres using the Proton system.

\section{Data validation and error correction}

Many of the local renal IT systems have limited field validation at the time of data entry. The UKRR therefore validates all fields that are not free text. The data management staff at the Registry contact the renal centre to discuss missing mandatory items and correction of other data errors. All coded fields are validated against the relevant code table. All numeric fields are checked that they contain only numeric data and are then validated against range checks. The findings of a case-note based validation exercise in all 5 renal centres in Wales were reported in 2005 [4].

\section{Special field checks}

1. The postcode is validated using a commercial postcoding package (QAS systems), which checks the validity of the postcode against the address fields, with the software automatically correcting the majority of postcode errors. Some cannot be resolved in an automated fashion and these require manual intervention. A correct validated postcode is important as they are used for NHS number tracing and also by the UKRR for PCT mapping and social deprivation scoring.

2. The NHS number is a unique numeric identifier for patients in England \& Wales (although still not in common usage within renal IT systems). This is stored in the UKRR database as a non-duplicated indexed field. The Registry submits files to the NHS number tracing service and liaises with centres over any data conflicts.

3. The UK Transplant number is a unique numeric identifier allocated by UK Transplant to patients that are on the UK transplant waiting list, or who have been transplanted in the UK (although it may be held only at the transplanting centre). This is stored in the UKRR database as a non-duplicated indexed field. The Registry validates these numbers annually with UK Transplant, with this process detecting mis-keyed data entry errors (e.g. 97074 instead of 90774). Renal centres are informed of any mis-keying errors found. 
4. The date of death field is received from renal centres and in England \& Wales also from the NHS Tracing service (validated through links with the Office for National Statistics, (which collects data on all births and deaths in these countries). Any subsequent data arriving after this date (e.g. laboratory or modality change) triggers a validation query.

\section{Avoidance of duplicate patients}

The UKRR receives patient data from both dialysis and transplant centres and if the right systems are not in place, it can be very easy for patients to be duplicated on the database.

Where NHS numbers are not sent, identification of duplicate patients is not just a simple process of flagging up patients with the same surname, forename and date of birth. Many patients have their names spelt in a slightly different way on different databases and it is impossible to impose consistency between two sites. In addition, dates of birth can vary (by days or months), and renal centres have been unwilling to change these data, partly perhaps because the local automated laboratory links may fail to load patient data if the date of birth or name is spelt differently from that held in the laboratory systems.

In addition to checking for uniqueness of the NHS number and any UK Transplant number before creation of a new patient record, there is a Soundex database index on names. The Soundex index is used on an annual database check for duplicate patients as it requires a lengthy manual intervention process on all queries.

\section{Logical rules}

In addition to simple range checks there are many logical rules e.g.

- a systolic blood pressure lower than the diastolic BP is rejected: this error frequently happens in this manual data entry field when an entry of 140 for example, may be mis-keyed as 14

- inappropriate data for specific treatment modalities: for example, a urea reduction ratio value or length of time on haemodialysis cannot be sent whilst the patient has a modality of peritoneal dialysis

- every patient must have at least one treatment modality entry.

\section{Pragmatic rules}

These are more complicated rules that are run on the database after each file load or on an annual data check.
1. There must be new patients starting RRT in every quarterly file received from the renal centre.

2. There must be some deaths in every quarterly file and the total number of deaths over a year should be evenly spread. A lack of deaths registered often represents a software extraction fault rather than an error of logging by the renal centre. An excess of deaths in a given quarter can also be identified and investigated.

3. Completeness for each data item submitted by a centre is compared with completeness in previous data extracts. Data items that have been previously sent from a centre and then become missing for all patients in a subsequent data extract are identified (e.g. ethnicity). This is usually due to local changes in the renal centre IT system. For instance, one site showed a large increase in missing urea reduction ratio data that had arisen from an undetected clerical error in storage of the post-dialysis sample data in the local database.

4. Duplicate notification of a renal transplant from both the transplant and dialysis centre is detected by checking the dates of transplantation. Patients with a second renal transplant within 4 weeks are identified. The date sent by the transplanting centre is always assumed to be the correct date and the duplicate entry is removed.

5. Data returns on the treatment timeline indicating that a patient has undergone transplantation in a non-transplanting centre are rejected and investigated.

6. Missing laboratory data over three consecutive quarters for an individual patient trigger investigation to check that that patient has not died or been transferred for follow-up elsewhere without completion of the appropriate treatment timeline entry.

7. Numerical values for each laboratory variable are compared from quarter to quarter. Identical values in three successive quarters trigger investigation, as this may be due to an error in the extraction software that results in extraction of an earlier value if no later value exists in the local database.

8. Annual prevalent patient numbers are expected to rise. A fall in stock of prevalent patients could be due either to transfer of a significant number of patients to a newly opened neighbouring centre, or to a data extraction problem.

9. Annual incidence rates are compared with previous years' data for each centre. Marked changes in either direction trigger investigation. 


\section{Statistical rules}

Statistical routines written in the SAS statistical language run further consistency checks on the annual data, for example:

1. Recheck on the final patient numbers.

2. Check the late presentation (referral) statistics. Is the percentage who were first seen by a nephrologist on the same day they started RRT believable? For most centres, up to $5 \%$ of new patients fall into this category. However, a few centres have $10 \%$ or more. For new patients in 2007 there were 6 centres which had values ranging from 22 to $100 \%$ and these were excluded from analysis.

3. Is there a difference between the pre-dialysis and post-dialysis blood pressure? Typically only 1 or $2 \%$ of patients have both readings exactly the same. A cut-off of $5 \%$ to highlight problems is used, so if both the pre-HD and post-HD systolic and diastolic BPs are identical for more than 5\% of a centre's patients for a quarter the data is likely to be invalid and indicates a possible software extraction error.

\section{Statistical analysis}

Data are extracted from the main database (without patient name or address identifiers) on an annual basis using SQL routines. These tables are then loaded into SAS, which separates data files into the analysis groups (e.g. incident patients by each year, prevalent patients by year, patients to be used for laboratory analyses, etc).

The majority of the analyses are coded in SAS, other packages (e.g. Stata, MLwin) are used when appropriate.

\section{Governance}

The work of the UKRR is prioritised by the UKRR Committee, which reports to the Clinical Affairs Board of the Renal Association, the professional body for nephrologists in the UK. The Chair of the UKRR Committee is appointed by the Trustees of the Renal Association (http://www.renal.org/pages/pages/the-association/ memorandum-articles-rules/rules-of-the-association.php). There are two subcommittees focusing on outcomes of dialysis and of transplantation. The business aspects of the UKRR are overseen by the Management Board, comprising the Trustees of the Renal Association together with the Director and General Manager of the UKRR. The Management Board is chaired by the immediate past President of the Renal Association. Suggestions for additional analyses are processed by the subcommittees and Committee. The UKRR provides occasional ad hoc analyses for the Department of Health, specialised commissioners and to support local or regional audit.

There is a need for clarity on the role of the Registry's responsibilities under the principles of clinical governance, particularly if an individual renal centre appears to be under-performing on one or more key measures of clinical activity. The process set out below has been agreed by the Clinical Affairs Board of the Renal Association.

The Registry Report is sent to the Chief Executives of all Trusts in which a renal centre is situated, since the responsibility for clinical governance within the Trust lies formally with the Chief Executive.

In the event that Registry analyses of data from a renal centre give rise to professional concern (e.g. mortality or transplantation rates), the data will first be validated internally by the Registry and then the source data checked with the reporting renal centre.

If the findings and analyses are robust and concern appears warranted, the Registry Chairman will notify the President of the Renal Association and will write to explain the findings to the clinical director or specialty lead of the relevant centre, asking that this information be passed to the Chief Executive of the Trust concerned and also to the Clinical Governance lead for that Trust. Written evidence of the internal hospital transfer of information should be received by the Renal Association within 8 weeks. If such evidence is not forthcoming the President will write to the Medical Director and Chief Executive of the Trust. The Renal Association can offer support (in terms of senior members providing advice) if requested by the Medical Director.

\section{Systems and data security}

\section{Systems}

There are no paper returns to the Renal Registry. The electronic patient data files are all processed on a Linux computer server. 
The computer server is located in the North Bristol NHS Trust's purpose built secure computer suite. Physical access to this room is restricted by hospital security protocols to senior IT staff. The Renal Registry has examined the physical security of the facilities and found these satisfactory.

The computer server has its own tape backup system, with the tape rotated on a daily basis by the hospital IT staff. These tapes are stored along with the hospital system backups, in the hospital's fire proof safe.

Access to the system is controlled by the security arrangements already in place to safeguard North Bristol NHS Trust, i.e. the hospital firewall. Access to the UKRR database server is only allowable from within the internal North Bristol NHS Trust network. Only the network hub from the Renal Registry is provided with a network connection through to the Registry computer server.

\section{Data Security and Integrity}

All users who are granted access to Renal Registry data have an individual and unique password allocated by the Systems Manager. Each user is assigned a level of security that determines the 'sensitivity' of the data that they can access. Only Registry employees are granted access to the data held by the Registry.

The Systems Manager is the only person who is granted access to the Registry systems at operating system level, all other users have their access controlled by their security level and are 'locked' into a menu system dependant upon that security level.

Any additions, amendments or deletions made to the data are recorded. 'Before' and 'after' images of the data are written together with the user name of the person making the change and the date and time of the change.

All communications involving patient identifiable data are encrypted using the open PGP standard [28], a public/private key system which supports the 256 bit Blowfish algorithm.

For data analysis, identifiable data (e.g. names, addresses, NHS numbers) are not extracted.

\section{Patient confidentiality and the National Health}

Service Act 2006 section 251 and the Health and

Social Care Act 2001: section 60 exemption

The UKRR collects information with patient identifiers including the name, postcode, date of birth, and NHS number. The collection of patient identifiable data without patient consent is regulated by statute National Health Service Act 2006, section 251. This was previously known as The Health and Social Care Act 2001: section 60, this renaming was due to the fact that every 10 years or so, the UK Parliament combines into a single legislative Act all the many Acts relating to the NHS and at the same time this process repeals all the previous NHS legislation.

The UKRR has been granted temporary exemption by the Secretary of State to hold patient identifiable data under section 251 of the National Health Service Act 2006. This exemption allows the registration of identifiable patient information from renal centres without first asking the consent of each individual patient, avoiding a breach of the common law on confidentiality. This exemption is temporary and is reviewed annually.

Patients have the right to ask that their identifiers are not submitted to the UKRR at the time of quarterly data returns and posters explaining this option are displayed in each renal centre.

The collection of patient identifiers enables the UKRR to perform data linkage with external datasets e.g. those held by UKT (for analyses of access to and outcomes from kidney transplantation). Permission for linkages to other datasets requires approval by the monitoring body for section 251 of the NHS Act 2006 (Patient Information Advisory Group) and the Registry is currently investigating linkages to the Health Protection Agency and the Hospital Episode Statistics database.

\section{Caldicott Requirements}

There has been recent concern in the UK over loss and insecure access to confidential information. The UK Registry is a recipient of patient identifiable data. The Caldicott guardian's job in each Trust is to make sure that any identifiable patient data that leaves the Trust site is authorised and complies with the Trusts current responsibilities and that the data held externally will remain secure.

The UKRR is registered under the Data Protection Act and this can be verified independently within the Trust using the following website (registration number Z8096557) http://www.esd.informationcommissioner. gov.uk/esd/search.asp.

The Registry also must apply for annual exemption under the NHS Act 2006 section 251 and Trusts may independently verify our listing on the official register using the following link (http://www.advisorybodies. doh.gov.uk/piag/register.htm).

Conflict of interest: none 


\section{References}

1 Ansell D, Feest T, Wallis J. British renal registry is fully electronic. $\mathrm{Br}$ Med J 1998;316(7129):471-2.

2 Hodsman A, Feest T, Ansell D, Tomson C. The UK Renal Registry: what makes it different from other national registries? British Journal of Renal Medicine 2007;12:28-31.

3 Tomson C, Ford D, Ansell D. The UK Renal Registry: an overview. Br J Hosp Med (Lond) 2008;69(10):548-9.

4 UK Renal Registry. Reflections on a Renal Unit Based Data Validation Exercise and Implications for National Renal IT. Chapter 17, UK Renal Registry 8th Annual Report, 2005.

5 Scottish Renal Registry. The Scottish Renal Registry Report 2002-2004, 2007. (http://www.srr.scot.nhs.uk/Report2004/Main.html)

6 Audit in renal failure; the wrong target? Br Med J (Clin Res Ed) 1981;283(6286):261-2.

7 Deaths from chronic renal failure under the age of 50. Medical Services Study Group of the Royal College of Physicians. Br Med J (Clin Res Ed) 1981;283(6286):283-6.

8 Treatment of and mortality from diabetic renal failure in patients identified in the 1985 United Kingdom survey. Joint Working Party on Diabetic Renal Failure of the British Diabetic Association, Renal Association, and the Research Unit of the Royal College of Physicians. BMJ 1989;299(6708):1135-6.

9 Berlyne GM. Over 50 and uremic equals death. The failure of the British National Health Service to provide adequate dialysis facilities. Nephron 1982;31(3):189-90.

10 Feest TG, Mistry CD, Grimes DS, Mallick NP. Incidence of advanced chronic renal failure and the need for end stage renal replacement treatment. Br Med J 1990;301(6757):897-900.

11 Roderick PJ, Ferris G, Feest TG. The provision of renal replacement therapy for adults in England and Wales: recent trends and future directions. QJM 1998;91(8):581-7.

12 Roderick P. Epidemiology of end-stage renal disease. Clin Med 2002;2(3):200-4.

13 Roderick P, Armitage A. Renal services for people with diabetes in the UK. Diabet Med 2002;19 Suppl 4:56-60.

14 Roderick P, Armitage A, Nicholson T, Mehta R, Gerard K, Mullee M, et al. A clinical and cost evaluation of hemodialysis in renal satellite units in England and Wales. Am J Kidney Dis 2004;44(1):121-31.
15 Feest TG, Rajamahesh J, Byrne C, Ahmad A, Ansell D, Burden R, et al. Trends in adult renal replacement therapy in the UK: 1982-2002. QJM 2005;98(1):21-8.

16 Blank L, Peters J, Lumsdon A, O’Donoghue D J, Feest TG, Scoble J, et al. Regional differences in the provision of adult renal dialysis services in the UK. QJM 2005;98(3):183-90.

17 NHS Blood and Transplant. Deceased kidney donation, 2009. (http:// www.uktransplant.org.uk/ukt/about_transplants/organ_allocation/kidney_(renal)/kidney_(renal).jsp)

18 Connecting for Health. What is QMAS?, 2009.

19 The Information Centre for Health and Social Care. QUALITY AND OUTCOMES FRAMEWORK 2007/8. Online GP practice results database, 2009.

20 Joint Specialty Committee for Renal Disease of the Royal College of Physicians of London and the Renal Association. Chronic kidney disease in adults: UK guidelines for Identification, Management, and Referral: Royal College of Physicians of London, 2006.

21 National Institute for Health and Clinical Excellence. Chronic Kidney Disease. Early identification and management of chronic kidney disease in adults in primary and secondary care. NICE clinical guideline 73, 2008.

22 Simpson K, Medcalf J, Stribling B. Functionality of renal computer systems. A report for the Renal Information Exchange Group, 2006. http://www.renal.org/rixg/RenalITfunctionality0406.pdf

23 Department of Health. The National Service Framework for Renal Services. Part One: Dialysis and Transplantation. London: Department of Health, 2004:1-50.

24 Department of Health. National Service Framework for Renal Services. Part Two: Chronic Kidney Disease, Acute Renal Failure, and End of Life Care. London: Department of Health, 2005:1-30.

25 Department of Health. Renal Services Information Strategy, 2004.

26 Department of Health. Renal Information Services Strategy. Supporting Part Two of the National Service Framework for Renal Services, 2005. (http://www.ic.nhs.uk/services/datasets/dataset-list/renal)

27 NHS Information Centre. http://www.connectingforhealth.nhs.uk/ dscn/dscn-2008/data-set-change-1/data-set-change

28 Open PGP standard. RFC 4880 http://tools.ietf.org/html/rfc4880 
